\title{
USULAN PERBAIKAN SISTEM KESELAMATAN DAN KESEHATAN KERJA PADA KAWASAN INDUSTRI DI KARAWANG
}

\author{
Haryadi Wibowo \\ Jurusan Teknik Kimia, Fakultas Teknik, Universitas Muhammadiyah Jakarta \\ Jl. Cempaka Putih Tengah 27 Jakarta 10510 \\ *E-mail : haryadi_wibowo@yahoo.com
}

\begin{abstract}
ABSTRAK
Salah satu wilayah yang dijadikan pusat industri di Karawang adalah kawasan industri Karawang International Industrial City (KIIC). Dengan luas sebesar 1200 Ha, banyak kegiatan industri yang terlibat didalamnya sehingga diperlukan suatu kajian kesehatan dan keselamatan kerja dalam lingkungan pada kawasan industri. Kajian kesehatan dan keselamatan kerja dalam kawasan industri KIIC telah dilakukan dengan metode yang digunakan adalah HIRA (Hazard Identification and Risk Assesment). Hasil yang didapatkan dengan menggunakan HIRA didapatkan sebanyak tiga belas potensi bahaya dalam kawasan industri dengan rekomendasi mitigasi yang perlu dilakukan adalah penanganan potensi longsor dan pemasangan pembatas. Untuk prioritas selanjutnya yang harus ditangani adalah belum adanya pos pemeriksaan pada batas wilayah, belum diterapkannya prosedur pemeriksaan pada setiap pos penjagaan, potensi terjatuh karena adanya kerusakan atau ketidakstabilan pada permukaan jalan.
\end{abstract}

Kata Kunci : HIRA, K3, Karawang, Kawasan Industri

\begin{abstract}
One of industrial area in Karawang is Karawang International Industrial City (KIIC). With 1200 Ha large area, there are so many industries and its activity in it. Thus, it will need safety study to ensure all activities running smoothly. This study had been studied using HIRA (Hazard Identification and Risk Assesment) Methode. Thirteen potential hazard resulted form HIRA and the recommendation for that potential hazard were handling of landslide and putting barrier for waterways and lake. Next priority were handling the absence of checkpoints on the border, the implementation of inspection procedures at every checkpoint, road damage .
\end{abstract}

Keywords : HIRA, Safety, Karawang, Industrial Area

\section{PENDAHULUAN}

Laju pertumbuhan ekonomi (LPE) Karawang relatif berfluktuasi, menyesuaikan kondisi perekonomian nasional serta kebijakan fiskal dan moneter Pemerintah. Selama periode 2006 - 2008, LPE berada di atas 5 persen atau berada di atas syarat terjadinya pertumbuhan secara minimal. Namun demikian, pada tahun 2009, terjadi perlambatan yang disebabkan turunnya pertumbuhan sektor industri yang terindikasi merupakan dampak dari penurunan kinerja perekonomian global pada tahun tersebut. Perkembangan PDRB ADHB periode 2006 - 2009 secara absolut terus mengalami 
peningkatan. Berdasarkan harga berlaku (current market price) pada tahun 2006 sebesar Rp. 31.348,37 Milyar meningkat hingga mencapai Rp. 47.225,24 Milyar di tahun 2009. Demikian pula atas dasar harga konstan (constant market price) dimana pada tahun 2006 dengan nilai Rp. 15.568,18 Milyar meningkat menjadi Rp. 19.195,45 Milyar di tahun 2009.

Hal tersebut berimbas pada sektor ketenagakerjaan dimana data jumlah angkatan kerja tahun 2008 berjumlah 981.245 jiwa, dengan jumlah pengangguran sebanyak 148.051 jiwa. Apabila dibandingkan dengan data tahun 2006, memperlihatkan adanya perbaikan kondisi ketenagakerjaan dimana angka pengangguran dapat ditekan dari sebesar $17,33 \%$ persen. Sedangkan dari jumlah penduduk Kabupaten Karawang yang bekerja menurut lapangan usaha sebesar 896.640 jiwa, sekitar 29,19\% atau sebesar 261.770 jiwa terserap pada lapangan usaha pertanian. Lapangan usaha perdagangan berada pada posisi kedua sebagai penyerap tenaga kerja dengan prosentase sebesar $26,27 \%$ atau sebesar 235.592 jiwa. Sedangkan pada lapangan usaha industri menyerap tenaga kerja sebesar sebesar $19,80 \%$ atau sebanyak 177.514.

Upaya perlindungan ketenagakerjaan masih diarahkan pada penanganan kasus perselisihan ketenagakerjaan yang relatif semakin menurun. Tercatat pada tahun 2006 terjadi 115 buah kasus dan pada tahun 2009 terjadi 92 kasus dan sudah tertangani. Tenaga kerja dibawah umur tentunya bertentangan dengan undang-undang ketenagakerjaan serta undang-undang pendidikan. Prosentase jumlah tenaga kerja dibawah umur di kabupaten karawang tergolong relatif kecil dari 896.640 orang pekerja hanya $0,02 \%$ atau hanya 1.828 orang tenaga kerja berusia 10-14 orang yang bekerja.

Upaya perlindungan ketenagakerjaan selain itu juga meliputi kesehatan dan keselamatan kerja bagi para pekerja ditempat kerja. Tempat kerja yang dimaksud dapat didefinisikan tempat langsung pekerja melakukan pekerjaannya dan juga lingkungan sekitarnya. Sebagai salah satu contoh tempat kerja bagi para pekerja di Kabupaten Karawang adalah kawasan industry Karawang International Industrial City (KIIC).

Dengan masih banyaknya kasus kasus kecelakaan kerja yang terjadi, maka sangatlah diperlukan suatu penelitian yang akan mengidentifikasi dan menganalisa bahaya ditempat kerja para pekerja. Dengan mengidentifikasi dan menganalisa potensi bahaya, pihak pemberi kerja dapat melakukan usaha mitigasi terhadap potensi bahaya yang mungkin terjadi dan pemerintah sebagai regulator dapat melakukan pengawasan dan penekanan terhadap penerapan peraturan kesehatan dan keselamatan pekerja.

Hasil kajian riset ini dapat menjadi benchmarking studi kesehatan dan keselamatan kerja di Indonesia dan dapat menjadi rekomendasi bagi pihak manajemen internal KIIC dan pemerintah Kabupaten Karawang sehingga dapat membantu meningkatkan kesejahteraan para pekerja dalam melakukan kegiatan pekerjaan dalam ruang lingkupnya masing-masing.

\section{METODE PENELITIAN}

Metode penelitian dalam bentuk kajian riset ini terbagi menjadi beberapa tahapan, yaitu dimulai dari tinjauan literatur mengenai kesehatan dan keselamatan kerja, melakukan perijinan kepada pihak terkait, melakukan mapping pada setia wilayah kawasan industri, melakukan noding pada area dan diakhiri dengan melakukan HIRA (Hazard Identification and Risk Assesment) pada setiap node/segmen area yang telah ditentukan

\section{HASIL DAN PEMBAHASAN}

Kawasan Industri Karawang International Industrial City (KIIC) yang terletak di Karawang Barat. KIIC dapat dijangkau dengan menggunakan kendaraan, baik dari tol maupun non toll. Jarak dari Kota Jakarta sekitar 50 km dengan menggunakan akses tol JakartaCikampek. Pengembangnya merupakan konsorsium perusahaan yang terdiri dari PT. Maligi Permata Industrial Estate, PT. Harapan Anang Bakri \& Son's, dan PT. Karawang Tata Bina Industrial Estate. Luas kawasan ini sekitar 1200 Hektar dengan jarak ke Pelabuhan Tanjung Priuk sekitar $60 \mathrm{Km}$ dan jarak ke Bandara Udara Internasional Soekarno-Hatta sekitar $70 \mathrm{~km}$. Dengan jarak yang relative tidak jauh dan akses tol menjadikan Kawasan 
Industri KIIC sebagai kawasan industri yang potensial untuk dikembangkan.

\section{Hazard Identification and Risk}

Assessment (HIRA) merupakan salah satu metode identifikasi kecelakaan kerja dengan penilaian risiko sebagai salah satu poin penting untuk mengimplementasikan Sistem Manajemen Keselamatan dan Kesehatan Kerja (SMK3). Dilakukannya HIRA bertujuan untuk mengidentifikasi potensi-potensi bahaya yang terdapat di suatu perusahaan untuk dinilai besarnya peluang terjadinya suatu kecelakaan atau kerugian.

Cara melakukan identifikasi bahaya dengan mengidentifikasi seluruh proses/area yang ada dalam segala kegiatan, mengidentifikasi sebanyak mungkin aspek keselamatan dan kesehatan kerja pada setiap proses/area yang telah diidentifikasi sebelumnya dan identifikasi K3 dilakukan pada suatu proses kerja baik pada kondisi normal, abnormal, emergency, dan maintenance.

Metodologi penelitian merupakan langkahlangkah yang akan dilakukan dalam penelitian untuk mencapai tujuan yang diinginkan. Tahapan yang dilakukan pada penelitian ini adalah:

1. Penguraian jenis pekerjaan, jenis kegiatan di urutkan berdasarkan urutan proses produksi yang diberikan oleh perusahaan. Urutan pekerjaan dilakukan dengan mengelompokan beberapa kegiatan.

2. Identifikasi potensi bahaya, potensi bahaya dapat dilakukan dengan melakukan pengamatan langsung di lantai produksi, pengamatan dilakukan untuk keseluruhan kegiatan yang dilakukan di lantai produksi tersebut.

3. penilaian keparahan dilakukan proses penilaian risiko dengan memperhatikan aspek penting keparahan (Severity). Penilaian keparahan dibagi kedalam 4 kategori yaitu catastropic, critical, marginal, neglicable. Severity diukur berdasarkan dampak terjadinya kecelakaan. Penilaian keparahan menggunakan tabel klasifikasi tingkat keparahan bahaya yang dapat dilihat pada Tabel 1.

4. Penilaian frekuensi, pada tahap ini dilakukan proses tingkat keseringan terjadinya kecelakaan atau kemungkinan munculnya bahaya dengan menggunakan tabel klasifikasi paparan bahaya yang dapat dilihat pada Tabel 2.

5. Menghitung besar nilai risiko yang dihasilkan dari sumber bahaya dapat diperoleh dengan menghitung nilai Risk Rating Number (RRN). Perhitungan Risk Rating Number dengan menggunakan rumus:

\section{RISK RATING NUMBER $=\mathrm{LO} \times \mathrm{DPH}$}

Keterangan:

$\mathrm{LO}=$ likelihood of occurance (Frequency)

$\mathrm{DPH}=$ Degree of possible harm (severity)

6. Indeks risiko bahaya, penilaian terhadap risiko diberikan nilai tertentu dengan mengkombinasikan tingkat kegawatan yang dapat terjadi maupun dari tingkat frekuensi terjadi bahaya dan risiko yang ditimbulkan dengan menggunakan kriteria usulan yang dapat dilihat pada Tabel 3 .

7. Prioritas risiko menggunakan tabel peta prioritas risiko yang dapat dilihat pada Tabel 4.

8. Setelah diketahui tingkat risiko yang dihasilkan maka dapat dibuat tabel HIRA.

Dengan luas area yang terlalu besar analisa kesehatan dan keselamatan kerja di lingkungan KIIC perlu dipersempit menjadi beberapa area kecil agar proses assestment HIRA dapat berjalan dengan efektif. Pembagian node dan hasil HIRA serta prioritas mitigasi dapat pada gambar 1 dan tabel 5 serta tabel 6 . 
Tabel 1. Klasifikasi Tingkat Keparahan Bahaya

\begin{tabular}{|c|c|c|c|}
\hline Description & Category & Score & Definition \\
\hline \multirow{2}{*}{ Catastrophic } & \multirow{2}{*}{ I } & \multirow{2}{*}{5} & Kematian \\
\hline & & & kehilangan system \\
\hline \multirow{4}{*}{ ritical } & \multirow{4}{*}{ II } & \multirow{4}{*}{4} & Luka berat yang menyebabkan cacat permanen \\
\hline & & & $\begin{array}{l}\text { Penyakit akibat kerja, memerlukan perawatan karena } \\
\text { tingkatnya yang parah }\end{array}$ \\
\hline & & & Kerusakan sistem yang berat \\
\hline & & & Kerugian finansial dalam jumlah besar \\
\hline \multirow{4}{*}{ Medium } & \multirow{4}{*}{ III } & \multirow{4}{*}{3} & Luka Medium yang menyebabkan cacat permanen \\
\hline & & & Penyakit akibat kerja, yang memerlukan perawatan \\
\hline & & & Kerusakan sistem yang menengah \\
\hline & & & Kerugian finansial dalam jumlah kecil \\
\hline \multirow{4}{*}{ Marginal } & \multirow{4}{*}{ IV } & \multirow{4}{*}{2} & Luka sedang, hanya membutuhkan perawatan medis \\
\hline & & & Penyakit akibat kerja yang ringan \\
\hline & & & Kerusakaan sebagian sistem \\
\hline & & & Kerugian finansial dalam jumlah kecil \\
\hline \multirow{2}{*}{ Neglicable } & \multirow{2}{*}{ V } & \multirow{2}{*}{1} & $\begin{array}{l}\text { Luka ringan yang hanya membutuhkan pertolongan } \\
\text { pertama }\end{array}$ \\
\hline & & & Kerusakan sebagian kecil sistem \\
\hline
\end{tabular}

Tabel 2. Klasifikasi Frekuensi Paparan Bahaya

\begin{tabular}{|c|c|c|l|}
\hline Description & Level & Score & \multicolumn{1}{|c|}{ Specific Individual Item } \\
\hline Frequent & A & 5 & Sering terjadi, berulang kali dalam sistem \\
\hline Probable & B & 4 & Terjadi beberapa kali dalam siklus sistem \\
\hline Occasional & C & 3 & Terjadi kadang-kadang dalam siklus sistem \\
\hline Remote & D & 2 & $\begin{array}{l}\text { Tidak pernah terjadi, tetapi mungkin terjadi dalam siklus } \\
\text { sistem }\end{array}$ \\
\hline Improbable & E & 1 & $\begin{array}{l}\text { Tidak mungkin, dapat diasumsikan tidak akan pernah terjadi } \\
\text { dalam sistem }\end{array}$ \\
\hline
\end{tabular}


Tabel 3. Indeks Risiko Bahaya

\begin{tabular}{|c|l|}
\hline Indeks Risiko Bahaya & \multicolumn{1}{c|}{ Kriteria Usulan } \\
\hline 1A, 1B, 1C, 2A, 2B, 3A & Tidak dapat diterima \\
\hline 1D, 2C, 2D, 3B, 3C & $\begin{array}{l}\text { Tidak diinginkan (membutuhkan keputusan aktivitas } \\
\text { manajemen) }\end{array}$ \\
\hline 1E, 2E, 3D, 3E, 4A, 4B & $\begin{array}{l}\text { Dapat diterima dengan peninjauan oleh aktivitas } \\
\text { manajemen }\end{array}$ \\
\hline 4C, 4D, 4E & Dapat diterima tanpa peninjauan manajemen \\
\hline
\end{tabular}

Tabel 4. Peta Prioritas Risiko

\begin{tabular}{|c|c|}
\hline RRN & PRIORITAS \\
\hline $0.1 \mathrm{~s} / \mathrm{d} 0.3$ & Prioritas paling rendah \\
\hline $0.4 \mathrm{~s} / \mathrm{d} 4$ & Prioritas rendah/risiko rendah \\
\hline $6 \mathrm{~s} / \mathrm{d} 9$ & Prioritas menengah/risiko yang signifikan \\
\hline $10<$ & Prioritas utama/dibutuhkan tindakan secepatnya \\
\hline
\end{tabular}

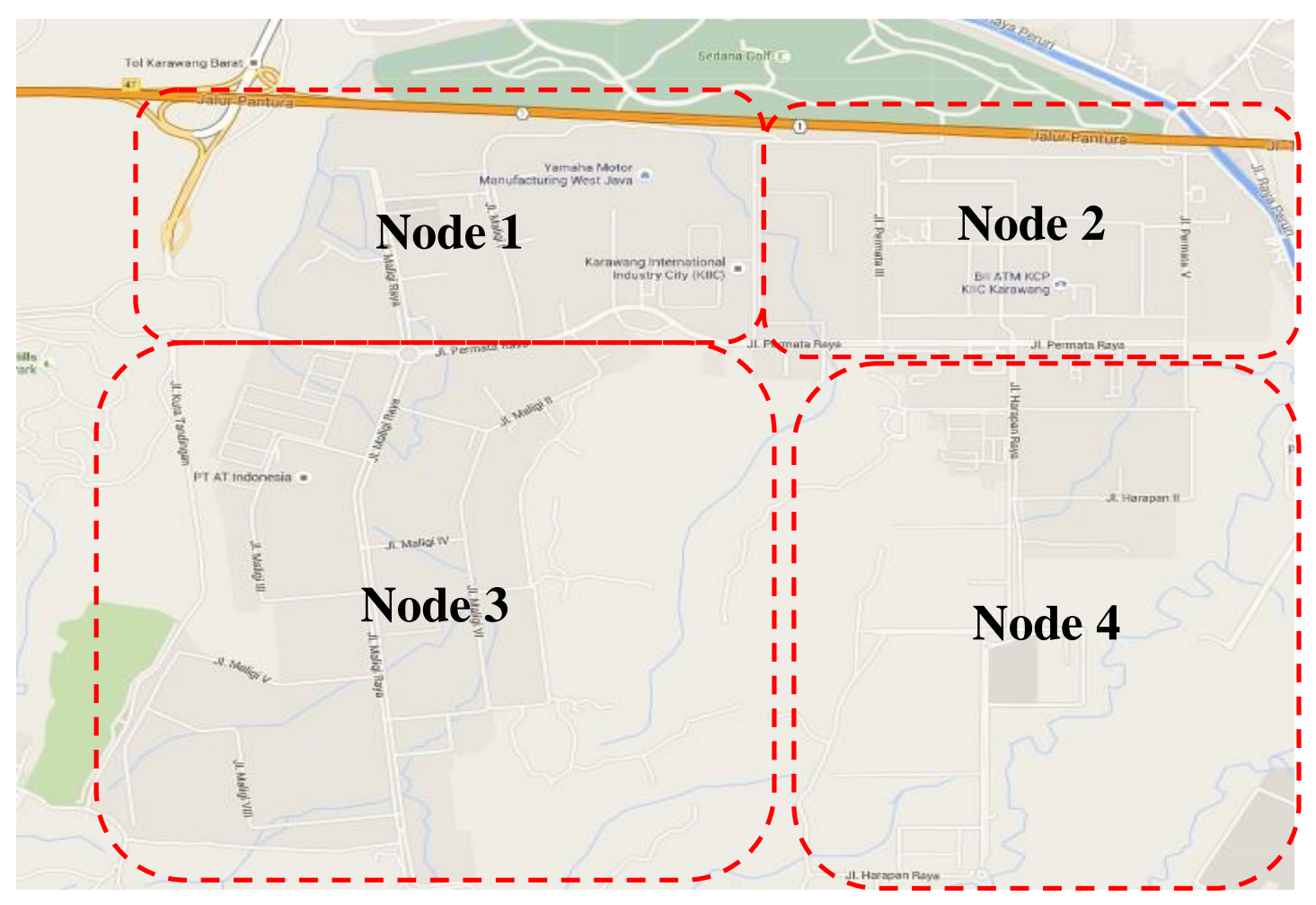

Gambar 1. Noding Kawasan Industri 
Tabel 5. HIRA Kawasan Industri KIIC

\begin{tabular}{|c|c|c|c|c|c|c|c|c|c|c|c|}
\hline \multirow{2}{*}{ No } & \multirow{2}{*}{ Node } & \multirow{2}{*}{$\begin{array}{c}\text { Lokasi Potensi } \\
\text { Bahaya }\end{array}$} & \multirow{2}{*}{$\begin{array}{l}\text { Identifikasi } \\
\text { Bahaya }\end{array}$} & \multirow{2}{*}{ Potensi Bahaya } & \multicolumn{2}{|c|}{ Severity } & \multicolumn{2}{|c|}{ Frekuensi } & \multirow{2}{*}{$\begin{array}{l}\text { Risk Rating } \\
\text { Number }\end{array}$} & \multirow{2}{*}{$\begin{array}{l}\text { Indeks } \\
\text { Risiko } \\
\text { Bahaya }\end{array}$} & \multirow{2}{*}{ Prioritas Risiko } \\
\hline & & & & & Category & Score & Level & Score & & & \\
\hline \multirow[t]{3}{*}{1} & \multirow{3}{*}{$\begin{array}{l}\overrightarrow{0} \\
\overrightarrow{0}\end{array}$} & Jl. Maligi Raya & Jalan rusak & Terjatuh & IV & 2 & c & 3 & 3 & $4 \mathrm{C}$ & Prioritas Menengah \\
\hline & & Jl. Permata I & Jalan rusak & Terjatuh & IV & 2 & c & 3 & 3 & $4 \mathrm{C}$ & Prioritas Menengah \\
\hline & & Jl. Maligi 1 & $\begin{array}{c}\text { Prosedur } \\
\text { pemeriksaan } \\
\text { belum berjalan }\end{array}$ & $\begin{array}{c}\text { Masuknya Orang/Barang } \\
\text { berbahaya }\end{array}$ & III & 3 & D & 2 & 4 & 3D & Prioritas Menengah \\
\hline \multirow[t]{3}{*}{2} & \multirow{3}{*}{$\begin{array}{l}\text { N } \\
\stackrel{0}{0} \\
2\end{array}$} & Jl. Permata III & Jalan rusak & Terjatuh & IV & 2 & C & 3 & 3 & $4 C$ & Prioritas Menengah \\
\hline & & Jl. Permata III & $\begin{array}{c}\text { Tidak ada pos } \\
\text { pemeriksaan }\end{array}$ & $\begin{array}{c}\text { Masuknya Orang/Barang } \\
\text { berbahaya }\end{array}$ & III & 3 & D & 2 & 4 & $3 \mathrm{D}$ & Prioritas Menengah \\
\hline & & Jl. Permata & Jalan rusak & Terjatuh & III & 3 & C & 3 & 3 & $3 C$ & Prioritas Menengah \\
\hline \multirow[t]{6}{*}{3} & \multirow{6}{*}{$\begin{array}{l}\text { m } \\
\stackrel{0}{0}\end{array}$} & Jl. Maligi Raya & pemeriksaan belun & $\begin{array}{c}\text { Masuknya Orang/Barang } \\
\text { berbahaya }\end{array}$ & IV & 2 & D & 2 & 4 & $4 \mathrm{D}$ & Prioritas Menengah \\
\hline & & Jl. Maligi V & $\begin{array}{l}\text { Tidak ada pos } \\
\text { pemeriksaan }\end{array}$ & $\begin{array}{c}\text { Masuknya Orang/Barang } \\
\text { berbahaya }\end{array}$ & IV & 2 & D & 2 & 4 & $4 \mathrm{D}$ & Prioritas Menengah \\
\hline & & Jl. Maligi VIII & Longsor & Berbahaya untuk transporasi & IV & 2 & $\mathrm{D}$ & 2 & 7 & $4 \mathrm{D}$ & Signifikan \\
\hline & & & & $\begin{array}{c}\text { Potensi pohon jatuh } \\
\text { menimpa } \\
\text { kendaraan/orang }\end{array}$ & IV & 2 & D & 2 & 7 & $4 \mathrm{D}$ & Signifikan \\
\hline & & Jl. Permata Raya & $\begin{array}{l}\text { Tidak ada pagar } \\
\text { pembatas danau }\end{array}$ & Terjatuh & III & 3 & c & 3 & 6 & $3 \mathrm{C}$ & Signifikan \\
\hline & & $\begin{array}{c}\text { Bundaran Jl. Maligi } \\
\text { Raya }\end{array}$ & $\begin{array}{l}\text { Tidak ada pagar } \\
\text { pembatas danau }\end{array}$ & Terjatuh & III & 3 & C & 3 & 6 & $3 C$ & Signifikan \\
\hline 4 & $\stackrel{+}{\stackrel{0}{\circ}}$ & $\begin{array}{l}\text { Ujung jalan Jl. } \\
\text { Harapan }\end{array}$ & $\begin{array}{l}\text { Tidak ada pos } \\
\text { pemeriksaan }\end{array}$ & $\begin{array}{c}\text { Masuknya Orang/Barang } \\
\text { berbahaya }\end{array}$ & IV & 2 & D & 2 & 4 & $4 \mathrm{D}$ & Prioritas Menengah \\
\hline
\end{tabular}

Tabel 6. Prioritas mitigasi potensi bahaya

\begin{tabular}{|c|c|c|c|c|c|c|}
\hline No & $\begin{array}{c}\text { Lokasi Potensi } \\
\text { Bahaya }\end{array}$ & Identifikasi Bahaya & Potensi Bahaya & $\begin{array}{l}\text { Risk Rating } \\
\text { Number }\end{array}$ & Prioritas Risiko & Mitigasi \\
\hline 1 & Jl. Maligi VIII & Longsor & Berbahaya untuk transporasi & 7 & Signifikan & $\begin{array}{c}\text { Pembuatan Dinding Penahan } \\
\text { Longsor }\end{array}$ \\
\hline 2 & Jl. Maligi VIII & Longsor & $\begin{array}{c}\text { Potensi pohon jatuh } \\
\text { menimpa } \\
\text { kendaraan/orang }\end{array}$ & 7 & Signifikan & $\begin{array}{l}\text { Pembuatan Dinding Penahan } \\
\text { Longsor }\end{array}$ \\
\hline 3 & Jl. Permata Raya & $\begin{array}{l}\text { Tidak ada pagar } \\
\text { pembatas danau }\end{array}$ & Terjatuh & 6 & Signifikan & Pemasangan Pagar \\
\hline 4 & $\begin{array}{c}\text { Bundaran Jl. Maligi } \\
\text { Raya }\end{array}$ & $\begin{array}{l}\text { Tidak ada pagar } \\
\text { pembatas danau }\end{array}$ & Terjatuh & 6 & Signifikan & Pemasangan Pagar \\
\hline 5 & Jl. Maligi 1 & $\begin{array}{l}\text { Prosedur pemeriksaan } \\
\text { belum berjalan }\end{array}$ & $\begin{array}{c}\text { Masuknya Orang/Barang } \\
\text { berbahaya }\end{array}$ & 4 & Prioritas Menengah & $\begin{array}{l}\text { Pembuatan dan pelaksanaan } \\
\text { SOP pemeriksaan di pos } \\
\text { penjagaan }\end{array}$ \\
\hline 6 & Jl. Permata III & $\begin{array}{l}\text { Tidak ada pos } \\
\text { pemeriksaan }\end{array}$ & $\begin{array}{c}\text { Masuknya Orang/Barang } \\
\text { berbahaya }\end{array}$ & 4 & Prioritas Menengah & $\begin{array}{c}\text { Pembuatan dan pelaksanaan } \\
\text { SOP pemeriksaan di pos } \\
\text { penjagaan }\end{array}$ \\
\hline 7 & Jl. Maligi Raya & $\begin{array}{l}\text { Prosedur pemeriksaan } \\
\text { belum berjalan }\end{array}$ & $\begin{array}{c}\text { Masuknya Orang/Barang } \\
\text { berbahaya }\end{array}$ & 4 & Prioritas Menengah & $\begin{array}{l}\text { Pembuatan dan pelaksanaan } \\
\text { SOP pemeriksaan di pos } \\
\text { penjagaan }\end{array}$ \\
\hline 8 & Jl. Maligi V & $\begin{array}{l}\text { Tidak ada pos } \\
\text { pemeriksaan }\end{array}$ & $\begin{array}{c}\text { Masuknya Orang/Barang } \\
\text { berbahaya }\end{array}$ & 4 & Prioritas Menengah & $\begin{array}{l}\text { Pembuatan pos penjagaan dan } \\
\text { pelaksanaan SOP pemeriksaan di } \\
\text { pos penjagaan }\end{array}$ \\
\hline 9 & $\begin{array}{l}\text { Ujung jalan Jl. } \\
\text { Harapan }\end{array}$ & $\begin{array}{l}\text { Tidak ada pos } \\
\text { pemeriksaan }\end{array}$ & $\begin{array}{c}\text { Masuknya Orang/Barang } \\
\text { berbahaya }\end{array}$ & 4 & Prioritas Menengah & $\begin{array}{l}\text { Pembuatan dan pelaksanaan } \\
\text { SOP pemeriksaan di pos } \\
\text { penjagaan }\end{array}$ \\
\hline 10 & Jl. Maligi Raya & Jalan rusak & Terjatuh & 3 & Prioritas Menengah & Diperbaiki \\
\hline 11 & Jl. Permata I & Jalan rusak & Terjatuh & 3 & Prioritas Menengah & Diperbaiki \\
\hline 12 & Jl. Permata III & Jalan rusak & Terjatuh & 3 & Prioritas Menengah & Diperbaiki \\
\hline 13 & JI. Permata & Jalan rusak & Terjatuh & 3 & Prioritas Menengah & Diperbaiki \\
\hline
\end{tabular}




\section{KESIMPULAN}

Dari penelitian yang sudah dilakukan, dapat diambil beberapa kesimpulan : penerapan metode HIRA pada kawasan industri menghasilkan tiga belas potensi bahaya yang terdapat dalam kawasan industri KIIC, dengan kategori risk rating number menengah sebanyak sembilan poin dan kategori signifikan sebanyak empat poin. Kategori yang termasuk ke dalam skala menengah adalah kondisi jalan yang rusak atau bergelombang dan tidak adanya prosedur pemeriksaan pada setiap pos perbatasan. Sementara untuk kategori skala yang signifikan adalah tidak adanya pagar pada area danau dan adanya potensi longsor.

Rekomendasi terkait potensi bahaya signifikan adalah pembuatan dinding penahan longsor dan pemasangan pagar pada sekitar area jalur/tempat air permukaan. Sedangkan pada potensi bahaya menengah direkomendasikan untuk membuat pos pemeriksaan, melaksanakan SOP pemeriksaan dan memperbaiki kondisi jalan yang rusak.

Selain itu, dapat disarankan agar dapat melakukan perbandingan dengan kawasan indsutri lainnya di sekitar kabupaten Karawang atau di sekitar Provinsi Jawa Barat. Dengan demikian, diharapkan didapatkan hasil yang lebih komprehensif terhadap penerapan HIRA pada suatu kawasan industri.

\section{DAFTAR PUSTAKA}

Amir Roehan, Kiki Rizki., Yuniar, Desrianty, Arie. 2014. Usulan Perbaikan Sistem Keselamatan dan Kesehatan Kerja (SMK3) Menggunakan Metode Hazard Identification and Risk Assestment (HIRA). Jurnal Online Institut Teknologi Nasional: No. 2, Vol. 02.

Indonesia, Bank. 2014. Kajian Ekonomi Regional Provinsi Jawa Barat Triwulan 4

Industry, Minister. 2012. Industrial Estates.

Directorate General of International Industrial Cooperation : Ministry of Industri of The Republic of Indonesia.

Kurniawati, Eni., Sugiono, Yuniarti, Rahmi. Analisis Potensi Kecelakaan Kerja pada Departemen Produksi Springbed dengan Metode Hazard Identification and Risk Assestment (HIRA).

Nurrachadiana, Cellica. 2014. Booklet Gambaran Umum Kabupaten Karawang Tahun 2013. Badan Perencanaan Pembangunan Daerah : Pemerintah Kabupaten Karawang.

Perindustrian, Menteri. 2010. Pedoman

Teknis Kawasan Industri No : 35/MIND/PER/3/2010 : Menteri Perindustrian Republik Indonesia

Security, Homeland. 2013. Threat and Hazard Identification and Risk Assesment Guide. Second Edition : Homeland Security. 